(1)
Volume 6, Nomor 2, Tahun 2020
Tersedia Online: http://ojs.uniska.ac.id/index.php/BKA
e-ISSN 2477-6300

\title{
PERAN GURU BK DENGAN LAYANAN INFORMASI DALAM MENGATASI KENAKALAN REMAJA BAGI SISWA KELAS X DI SMK TUNAS BANGSA
}

\author{
Syarifah Raudatul Jannah, Gusti Irhamni, Zainal Fauzi \\ Program Studi Bimbingan dan Konseling, Universitas Islam Kalimantan Muhammad Arsyad Al Banjari \\ E-mail : owdachassegaf3@gmail.com
}

\begin{abstract}
ABSTRAK
Tujuan penelitian ini adalah untuk mengetahui layanan informasi yang berjalan saat ini dan untuk mengetahui peran layanan informasi dalam mengangani kenakalan remaja pada siswa kelas X SMK Tunas Bangsa. Desain penelitian yang digunakan yaitu metode kualitatif.. Adapun jumlah sampel yang dibutuhkan dalam penelitian ini dengan lima orang siswa yaitu dengan meminta bantuan guru BK memilih beberapa siswa untuk mewawancara dan memberikan layanan informasi kepada lima orang siswa. Teknik analisis data yang digunakan yaitu wawancara, dan observasi. Dari hasil penelitian dapat ditari kesimpulan layanan informasi yang deiberikan untuk memberikan pemahaman kepada siswa tentang kenakalan remaja terutama tentang informasi yang dibutuhkan dan bisa membantu siswa dalam mengambil keputusan yang tepat dan ditemukannya bentuk kenalakan remaja yang ada di SMK Tunas Bangsa yaitu terlambat masuk sekolah, membolos, menyontek dan melanggar peratusan sekolah. Sarannya untuk guru bimingan konseling diharapkan lebih memberikan informasi sebnyak-banyaknya kepada siswa terkait dengan kenakalan remaja.
\end{abstract}

Kata Kunci: Peran Guru; Layanan Informasi; Kenakalan Remaja

\begin{abstract}
The purpose of this study was to determine information services currently running and to determine the role of information services in dealing with juvenile delinquency in class X SMK Tunas Bangsa students. The research design used is a qualitative method. The number of samples needed in this study with five students, namely by asking the guidance counselor to select several students to interview and provide information services to five students. The data analysis techniques used were interviews and observation. From the research results can be drawn the conclusion of the information services provided to provide understanding to students about juvenile delinquency, especially about the information needed and can help students in making the right decisions and finding forms of adolescent acquaintance in SMK Tunas Bangsa, namely late entry to school, truancy, cheating and violating school requirements. The suggestion for counseling guidance teachers is that it is hoped that they will provide as much information as possible to students regarding juvenile delinquency.
\end{abstract}

Keywords: Teacher Role, Information Services, Juvenile Delinquency 


\section{PENDAHULUAN}

Lembaga pendidikan adalah suatu institusi atau tempat dimana proses pendidikan atau belajarmengajar berlangsung, diantaranya pendidikan di dalam keluarga, sekolah, dan masyarakat. Lembaga pendidikan juga dapat didefinisikan sebagai suatu organisasi yang dibentuk untuk mencapai tujuan tertentu, yaitu transfer ilmu pengetahuan dan budaya kepada individu untuk mengubah tingkah laku seseorang menjadi lebih dewasa dan memperoleh kehidupan yang lebih baik di masa depan. Tujuan utama dari lembaga ini adalah untuk mengubah tingkah laku peserta didik menjadi lebih baik melalui interaksi dengan lingkungan di sekitarnya. Dengan kata lain, lembaga ini sangat dibutuhkan oleh masyarakat karena dapat meningkatkan kualitas hidup seseorang (Abidin, \& Budiono, 2010).

Mencapai kehidupan yang baik, harus ada bimbingan yang terarah. Bimbingan yang terarah dalam hal ini adalah proses perkembangan dengan melalui proses belajar dengan disebut pengajaran. Namun pengajaran tidak dapat menjangkau psikologis yang bersifat pribadi. Oleh karena itu masih diperlukan bimbingan dan konseling untuk dapat memberikan bimbingan terhadap proses perkembangan siswa tersebut. banyak kejadian yang sering terjadi pada anak kelas X, seperti membolos, terlambat masuk sekolah, berkelahi, berbohong dan melanggar aturan sekolah. Perbuatan- perbuatan tersebut membutuhkan penangan dari guru bimbingan konseling di sekolah (Hellen, 2002).

Dengan adanya bimbingan yang diberikan, berupa informasi yaang terkait dengan pengertian kenakalan siswa, jenis kenakalan, faktor yang mempengaruhi, bentuk kenakalan dan akibat-akibat dari kenakalan. Sehingga dengan pengetahuan tersebut siswa diharapkandapat bertindak dengan sangat hati-hati dan benar dalam perbuatannya.

Bimbingan dan konseling bertujuan membantu peserta didik mencapai tugas-tugas perkembangan secara optimal sebagai makhluk Tuhan, sosial, dan pribadi (Winkel \& Hastuti, 2012). Dalam hal ini terdapat beberapa layanan yang ada dalam bimbingan dan konseling, salah satunya adalah layanan informasi (Prayitno, 2012). Layanan informasi ini bertujuan untuk membekali para siswa dengan pengetahuan tentang data dan fakta dibidang pendidikan sekolah, bidang pekerjaan dan bidang perkembangan pribadi-sosial, supaya mereka dapat belajar tentang lingkungan hidupnya mampu mengatur dan merencanakan kehidupannya sendiri. Layanan informasi dipilih peneliti karena layanan informasi merupakan salah satu layanan yang dapat memebantu dan menyelesaikan permasalahan peserta didik dalam mencegah dari perilaku-perilaku negatif yang tidak sesuai dengan norma-norma yang ada disekolah maupun dimasyarakat.

Menurut Gunawan (2010:89) mendefinisikan kenakalan siswa adalah perbuatan anti sosial yang dilakukan anak/remaja yang bila dilakukan oleh orang dewasa dikategorikan sebagai tindak kejahatan. Perbuatan anak-anak yang melanggar norma sosial, norma hukum, norma kelompok dan mengganggu ketemtraman masyarakat, sehingga yang berwajib terpaksa mengambil tindakan pengamanan/penangkalan bila kenakalan dilakukan oleh orang dewasa/tua disebut kejahatan (Ma'mur, 2011).

Penelitian yang dilakukan oleh Dahlia, Yakub dan Saam (2018) menunjukkan bahwa gambaran jenis-jenis kenakalan remaja berada dalam kategori rendah. Kenakalan remaja antara lain perkelahian, pemaksaan, menyakiti fisik seseorang, perusakan, pencurian, tidak menjaga harga diri dan kehormatan, penyalahgunaan obat, mengkonsumsi alcohol, mengunakan media pornografi, membolos sekolah, terlambat datang ke sekolah, tidak memakai atribut lengkap di sekolah, merokok di dalam lingkungan sekolah, mencontek di kelas serta berbohong kepada guru dan teman. Kenakalan berada pada kategori rendah karena adanya peranan guru BK dalam mengatasi kenakalan remaja pada kategori baik. Guru BK mengatasi kenakalan remaja dengan melakukan tindakan preventif yaitu melakukan kegiatan keagamaan, kegiatan ekstrakulikuler, memberikan motivasi, layanan orientasi, layanan informasi, bimbingan kelompok, layanan pengumpulan data, dan layanan media. Tindakan kuratif yaitu melatih disiplin, tertib, dan teratur, melakukan rekreasi sehat dengan disiplin tinggi, menggiatkan organisasi pemuda, konseling, tindak lanjut dan alih tangan kasus. Tindakan pepretif yaitu peringatan lisan maupun tertulis, punishment, home visit dan melibatkan seluruh komponen (Ahmad, 2007).

Ada dua faktor yang dinilai memiliki peranan besar terhadap perilaku siswa, bisa jadi dari siswa itu sendiri (intern) maupun lingkungannya (Ekstern). Dan faktor-faktor tersebut dapat dihindari melalui lingkungan keluarga, lingkungan sekolah dan lingkungan masyarakat. Faktor yang berasaldari anak itu sendiri, yaitu : penyakit syaraf, penyakit jiwa, dorongan nafsuyang berlebihan, penilaian yang tidak tepatkepada diri sendiri dan orang lain, serta pandangan terhadapdiri sendiri yang negatif. Dan faktor lingkungan adalah: keadaan ekonomi masyarakat, masa atau peralihan, keretakan rumah tangga, praktek-praktek mengasuh anak, pengaruh temn sebaya dan pengaru pelaksanaan hukum. 
Syarifah Raudatul Jannah, Gusti Irhamni, Zainal Fauzi

Jurnal Bimbingan dan Konseling Ar-Rahman

Volume 6, Nomor 2, Tahun 2020

e-ISSN 2477-6300

Kebanyakan perilaku negatif tersebut banyak dilakukan oleh siswa yang menginjak masa remaja. Remaja mengalami badai dan topan dalam kehidupan perasaan dan emosinya. Remaja sesekali sangat bergairah dalam bekerja tiba tiba berganti lesu, kegembiraan yang meledak bertukar rasa sedih yang sangat, rasa percaya diri berganti rasa ragu ragu yang berlebihan, termasuk ketidak tentuan dalam menentukan cita cita dan menentukan hal-hal yang lain (Santrock, 2014). Dimasa ini sering kita mengenalnya yaitu masa labil, dimana kita merasakan ketidak tentuan perasaan kita, karena adanya pengaruh baik dari luar maupun dari dalam. Dengan kondisi siswa yang demikian, maka guru BK mempunyai tanggung jawab untuk memberikan bimbingan yang baik, hal ini dapat dilakukan dengan cara memberikan informasi yang tepat dan benar kepada siswa, sehingga dapat mencegah dari perbuatan negatif, karan banyaknya pengetahuan dan informasi yang siswa ketahui.

\section{METODE}

Penelitian ini menggunakan metode penelitian kualitatif. Sumber data yang digunakan yaitu data primer dan data sekunder. Teknik pengumpulan data yang digunakan yaitu dengan cara wawancara dan observasi. Dalam melakukan penelitian teknik analisis data digunakan untuk menyusun, mengolah dan menghubungkan yang sudah diperoleh (Moleong, 1989; Bungin, 2001; Sugiyono, 2015). Penelitian ini dilaksanakan di SMK Tunas Bangsa Batulicin Kabupaten Tanah Bumbu yang beralama di Jl Raya Batulicin Jl.Manggis Km 5 Kecamatan Batulicin Kabupaten Tanah Bumbu.

\section{HASIL DAN PEMBAHASAN}

Hasil penelitian yang dilakukan melalui observasi dan wawancara kepada guru BK dan lima siswa, terdapat beberapa kesimpulan yaitu:

1. Tujuan Guru Bk dalam pemberian layanan informasi untuk memberikan pemahaman kepada siswa tentang informasi yang dibutuhkan dan bisa membantu siswa mengambil keputusan dengan tepat. Layanan informasi yang diberikan oleh guru BK untuk materi yang diberikan tergantung dengan kondisi yang ad disekolah saat itu.

2. Layanan informasi untuk mengatasi kenakalan remaja sangat berperan penting dimana layanan informasi merupakan salah satu layanan yang wajib diberikan kepada siswa, agar siswa mengetahui manfaat dan akibat yang diperoleh dari perilaku siswa yang dilakukan.

3. Kenakalan remaja yang sering terjadi yaitu: terlambat masuk sekolah, membolos, menyontek, melanggar peraturan sekolah.
Adapun penanganan yang dilakukan dengan kesepakatan guru Bk dan Wali kelas dengan memberikan Surat pemanggilan orang tua dan kedua apabila melakukan kesalahan yang sama maka akan diberikan sanksi membuat surat pernyataan dengan materai.

4. Dalam pemberian layanan informasi selain yang disampaikan dengan guru Bk yaitu adanya kerjasama dengan pihak luar untuk pemberian layanan informasi yaitu dengan adanya sosialisasi dari puskesmas dengan memberikan materi seperti seks bebas dan juga adanya kerjasama dengan pihak kepolisian atau BNN untuk datang memberikan materi tentnag bahaya narkoba.

5. Faktor terjadinya kenakalan remaja yaitu karena kurangnya pengawasan orang tua, jarak rumah yang jauh, dan lingkungan yang kurang baik.

Berdasarkan dari hasil penelitian yang yang telah dilakukan dapat ditarik kesimpulan sebagai berikut:

1. Layanan informasi diberikan untuk memberikan pemahaman kepada siswa tentang kenakalan remaja terutama tentang informasi yang dibutuhkan dan bisa membantu siswa mengambil keputusan yang tepat. Adapum cara layanan informasi di SMK Tunas Bangsa diberikan yaitu dengan metode ceramah, metode diskusi dan buku panduan

2. Guru BK memberikan layanan informasi merupakan layanan yang wajib dimana agar siswa dapat mengetahui manfaat dan akibat dari perilaku siswa yang telah melakukan kenakalan remaja

3. Adapun bentuk kenakalan remaja yang ada di SMK Tunas Bangsa yaitu, terlambat masuk sekolah, membolos, menyontek, dan melanggar peraturan sekolah.

Dalam penelitian ini, ditemukan bahwa layanan Bimbingan dan Konseling yang diberikan yaitu berupa layanan Informasi. Layanan informasi, adalah layanan bimbingan dan konseling yang memungkinkan peserta didik (klien) menerima dan memahami berbagai informasi (seperti informasi pendidikan dan informasi jabatan) yang dapat digunakan sebagai bahan pertimbangan dan pengambilan keputusan untuk kepentingan peserta didik (Prayitno \& Amti, 2014: 55).

Layanan informasi juga bermakna usahausahauntuk membekali peserta didik dengan pengetahuan serta pemahaman tentang lingkungan hidupnya. (Tohirin. 2009:76). Komponen Layanan Informasi Dalam layanan informasi terlibat tiga 
komponen pokok, yaitu konselor, peserta, dan informasi yang menjadi isi layanan :

a. Konselor ( guru pembimbing) Konselor, ahli dalam pelayanan konseling adalah penyelenggara layana informasi. Konselor menguasai sepenuhnya informasiyang menjadi informasi layanan, mengenal dengan baik peserta layanan dan kebutuhanya kan informasi, dan menggunakan cara-cara yang efektif untuk melaksanakan layanan.

b. Peserta Peserta layanan informasi dapat berasal dari berbagai kalangan, siswa sekolah, mahasiswa, anggota organisasi pemuda dan sosialpolitik,karyawan instansi dan dunia usaha/industru,serta anggota-anggota masyarakat lainya baik secara perorangan maupun kelompok. Layanan informasi di sekolah pesertanya adalah peserta didik. peserta didik, menurut undang-undang republik indonesia tentang sistem pendidikan nasional adalah anggota masyarakat yang berusaha mengembangkan dirinya melalui prosesnya pendidikan pada jalur, jenjang dan jenis tertentu.

c. Informasi Jenis, luas dan kedalaman informasi yang menjadi isi layanan informasi sangat bervariasi. Lebih rinci berbagai informasi dapat digolongkan kedalam:

- Informasi perkembangan diri

- Informasi hubungan pribdi,sosial, nilai dan moral

- Informasi pendidikan, kegiatan belajar, dan keilmuan tekhnologi

- Informasi sosial budaya, politik, dan kewarganegaraan

- Informasi pekerjaan dan ekonomi

- Informasi kehidupan berkeluarga

- Informasi kehidupan berkeluarga

Selain itu, ditemukan pula bahwa secara fenomelogis tampak bahwa gejala kenakalan timbul dalam masa pubertas/pancaroba, dimana jiwa dalam keadaan labil, sehingga mudah terseret dalam lingkungan. Widharto (2007) mengemukakan bahwa seorang anak tidak tiba-tiba menjadi nakal, tetapi menjadi nakal karena beberapa saat setelah dibentuk oleh lingkungannya (keluarga, sekolah, masyarakat) termasuk kesempatan yang diluar kontrol yaitu:

a. Lingkungan keluarga yang pecah, kurang perhatian, kurang kasih sayang

b. Situasi (rumah tangga, sekolah, lingkungan) yang menjemukan dan membosankan padahal tempat tersebut mestinya dapat merupakan faktor penting untuk mencegah kenakalan bagi anak-anak. c. Lingkungan masyarakat yang tidak/kurang menentu bagi prospek kehidupan masa mendatang, seperti masyarakat yang penug spekulasi, korupsi, manipulasi, gosip, isu-isu negatif/destruktif, perbedaan terlalu mencolok (Gunawan, 2010:93)

Dari pendapat diatas dapat disimpulkan bahwa kewajiban dan tugas kita semua baik orang tua, pendidik (guru) dan pemerintah untuk mempersiapkan generasi muda menjadi generasi yang tangguh dan berwawasan atau berpengetahuan yang luas dengan jalan membimbing dan menjadikan mereka semua sehingga menjadi warga Negara yang baik dan bertanggung jawab secara moral.

\section{PENUTUP}

Kesimpulan yang dapat ditarik dari pembahasan dan hasil penelitian yang diuraikan, dapat ditarik kesimpulan sebagai berikut:

1. Layanan informasi yang berjalan saat ini diberikan untuk memberikan pemahaman kepada siswa tentang kenakalan remaja terutama tentang informasi yang dibutuhkan dan bisa membantu siswa mengambil keputusan yang tepat. Adapum cara layanan informasi di SMK Tunas Bangsa diberikan yaitu dengan metode ceramah, metode diskusi dan buku panduan

2. Peran Guru BK memberikan layanan informasi merupakan layanan yang wajib dimana agar siswa dapat mengetahui manfaat dan akibat dari perilaku siswa yang telah melakukan kenakalan remaja

3. Faktor penyebab kenakalan remaja yang ada yaitu karena kurangnya pengawasan dari orang tua, jarak rumah yang jauh dan lingkungan yang kurang baik. Adapun bentuk kenakalan remaja yang ada di SMK Tunas Bangsa yaitu, terlambat masuk sekolah, membolos, menyontek, dan melanggar peraturan sekolah.

Berdasarkan simpulan tersebut, penulis menyarankan kepada:

1. Bagi guru bimbingan dan konseling diharapkan lebih memberikan informasi sebanyakbanyaknya kepada siswa terkait dengan kenakalan remaja dan

2. informasi yang dibutuhkan siswa agar siswa lebih memahami, mengerti dan bisa mengambil keputusan dengan baik dan benar.

3. Bagi peneliti selanjutnya diharapkan ada penelitian yang lebih lanjut dan mendalam sehubungan dengan layanan informasi untuk mengatasi kenakalan remaja, demi kesempurnaan penelitian ini di masa yang akan datanag, karena walaupun penulis sudah 
Syarifah Raudatul Jannah, Gusti Irhamni, Zainal Fauzi

Jurnal Bimbingan dan Konseling Ar-Rahman

Volume 6, Nomor 2, Tahun 2020

e-ISSN 2477-6300

maksimal dalam mengerjakannya, namun masih penulis sadari masih jauh dari kesempurnaan dan dapat bermanfaat bagi pelaksanaan BK di sekolah.

\section{REFERENSI}

Abidin, Z., \& Budiono, A. (2010). Dasar-dasar Bimbingan dan Konseling. Yogyakarta: Grafindo Litera Media.

Ahmad, A.B. (2007) Peran Guru Bimbingan dan Konseling dalam Mengatasi Kenakalan Siswa di MAN 1 Model Bengkulu, Fakultas dakwah UIN Sunan Kali Jaga Yogyakarta.

Arikunto, S. (2014). Prosedur Penelitian Suatu Pendekatan Praktik. Jakarta: Rineka Cipta.

Basri, S. \& Zain, A. (1996). Strategi Belajar Mengajar, Jakarta : PT. Rineka Cipta

Bungin, B. (2001). Metodologi Penelitian Kualitatif (Aktualisasi Metodologis ke Arah Ragam Varian Kontemporer), Jakarta, PT RajaGrafindo Persada

Departemen Agama. (1989). Al-Qur'an dan Terjemahannya. Jakarta: Departemen Agama.

Prayitno dan Amti, E. (2014). Dasar-dasar Bimbingan dan Konseling. Jakarta: Rineka Cipta.

Hallen A. (2002). Bimbingan Konseling, Jakarta: Ciputra Pers

Kusumawati, E. (2018). Pengaruh Layanan Informasi Bahaya Merokok Terhadap Motivasi Merokok Pada Siswa Smk Warga Surakarta Universitas Tunas Pembangunan Jurnal Ilmiah Mitra Swara Ganesha, 5 (1).

Ma'mur, A.J. (2011). Kiat Mengatasi Kenakalan Remaja di Sekolah, Yogyakarta: Buku Biru

Moleong, L.J. (1989), Metodologi Penelitian Kualitatif, Bandung : Remaja Rosda Karya

Santrock, J.W. (2014). Adolescence Perkembangan Remaja, Jakarta : Erlangga

Soehartono, I. (2004). Metode Penelitian Sosial, Bandung: PT Remaja Rosdakarya

Sugiyono. (2015). Metode Penelitian Pendidikan. Bandung: Alfabeta.

Tohirin. (2007). Bimbingan dan Konseling di Sekolah dan Madrasah. Pekanbaru:Grafindo Persada.

Widharto. (2007). Stop Mirasantika. Jakarta: Sunda Kelapa Pustaka.

Winkel, \& Hastuti, S. (2012). Bimbingan Dan Konseling di Institusi pendidikan, Jakarta: Media Abadi 